\title{
Fernando Uriarte
}

\section{La lectura problemática de Ortega"}

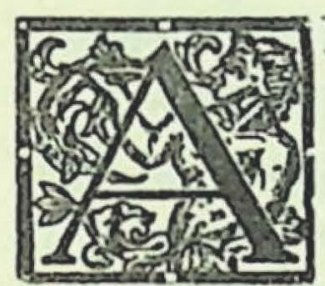

NTES de la edición de las Obras Completas, por la "Revista de Occidente" en 1946, escasas personas han podido leer a Ortega y Gasset en orden cronológico. La gran mayoría, integrada por lectores de continentes lejanos y aun de españoles ajenos al círculo intelectual íntimo del filósofo, recibió el mensaje que le estaba dedicado ignorando el gran propósito que lo inspiraba, visible apenas para quien recibe una explicación previa o practica una lectura ordenada.

La consecuencia inmediata del desorden en que incurría, involuntariamente, el lector, es la permanente revisión - releer fructífero y laborioso- rica en sorpresas, en súbitas iluminaciones, a que se ven forzados los exploradores de esta frondosa filosofía, de apariencia sencilla y enunciación luminosa.

Empezamos con cualquier libro. Por ejemplo: España invertebrada, o La rebelión de las masas, o Personas, obras, cosas; todo se entiende muy bien. Hollamos un suelo intelectual prodigioso, sobremanera nutritivo, llevados de la mano, a través de la espesa maraña del problema planteado y todas sus implicaciones, por una mente clara, especie de genio anatómico inclinado sobre las ideas y los hechos. Ortega galvaniza, en su aguda disociación, grandes zonas del saber humano y, a poco andar, la carne hermética de nuevas ver- 
dades lanzan rayos desconocidos y sorpresivos. Queda el lector muy bien servido, pero le acosa la sensación de que algo se le va escapando.

Se emprende la lectura de otro libro, El tema de nuestro tiempo pongamos por caso, y el panorama intelectual se ensancha estimulándonos de modo abusivo, pero la curiosa sensación persiste. Por lo pronto es posible observar que no se trata de libros aislados, distintos; cada uno supone, o contiene, al otro, como si el epígrafe anunciara variaciones sobre el mismo asunto, que los conecta y entreteje sistemáticamente.

Se supone con razón a estas alturas que debe haber un escrito, lleno de potencia, que contenga en germen a todos, del que pueden predicarse claramente; un núcleo germinal integrador, en suma.

Esta caída en la cuenta - frase habitual del maestro- se produce necesariamente, cuando se lee con honradez. En Pidiendo un Goethe desde dentro, tardíamente para el caso, quebró Ortega su silencio y su desdén, decidiéndose a prestar ayuda aclaratoria, bien que de manera decisiva.

Tiene su encanto el difícil e incierto camino que nos lleva hasta aquel libro lejano, escrito a los veintiséis años, donde se enuncia la clave de lo que empezamos a intuir, en virtud de la cual, la aparente particularidad de los problemas examinados en cada libro -aislamiento en que los situaba nuestra ignorancia-, desaparece, se diseña vagamente una integración sistemática, adquieren una significación precisa y unitaria, se despliega un amplio follaje ideológico y se siente palpitar por debajo de lo escrito una suerte de mágica interrelación armónica.

Este pequeño libro genial que proyecta la luz indispensable y necesaria a la comprensión de toda la obra se llama Meditaciones del Quijote. El espectáculo de una vida filosófica y de una filosofía que, para enunciarse plenamente, debe concretarse en vida, en hacer, se abre de golpe ante el desorientado lector. Se trata de una filosofía que prueba su eficacia, su verdad, siendo vida. Aquí no se propone una doctrina con el fin de enhebrar luego una exposición crítica de sus supuestos, sino que la obra entera va a constituir "un caso ejecu- 
tivo de la misma doctrina", al decir de Ortega. Esta vez el movimiento se prueba andando.

Meditaciones del Quijote revela el germen de los futuros desarrollos y muestra el instante en que la nueva realidad ontolbgica se hace visible. Ortega aclara el asunto, años después, en Historia como sistema. Se trataría de algo así como una idea, o mejor, de un poro a través del cual penetró en la conciencia del pensador algo "ultra mental, algo trascendente que, sin intermedio, late pavorosamente bajo nuestra mano". Ortega comprime el fenómeno hasta el límite cuando agrega que hay en esto algo así como "un puro modo de patética presencia que una realidad absoluta elige”, permitiendo que "lo trascendente se nos descubra por sí mismo, nos invada e inunde -y esto es la revelación".

Meditaciones del Quijote patentiza esta revelación; se la ve venir con una fuerza sonriente y tranquila al correr de la pluma del escritor, que a los veintiséis años, descubre, frenético y asombrado, la realidad a quema ropa. La curiosidad del lector queda imantada, enérgicamente dirigida. En adelante cada libro, ensayo o artículo del autor, le llevará a constatar la eficacia de la idea-germen y le impondrá deberes de autoexamen, de vigilancia alerta, estimulado, en cierta medida, a una modesta colaboración.

Ortega fué responsable, en gran parte, del retardo en la intelección de sus escritos. El método para aminorar esta tardanza consiste en una lectura atenta y cronológica. El filósofo no se preocupó como habría sido conveniente, y perdonable, de gritar su hallazgo, cobijándolo bajo un título más orientador que el de Meditaciones del Quijote, que escamotea, o encubre, el verdadero asunto. Manuel Granell, en su Lógica, ha señalado esta inclinación de Ortega a los títulos más literarios que filosóficos. Acomodaba así su labor a la escasa densidad del clima intelectual español para la filosofía y se sometía, cortésmente, a la circunstancia, tratando de "seducir hacia los problemas filosóficos con medios líricos".

Una fórmula tan simple como "Yo soy yo y mi circunstancia" encierra en su inocente elementalidad la doctrina profunda y el im- 
perativo de consumir cada hora, de quemar cada libro, en holocausto a la sencilla frase.

Se debe guardar la máxima cautela con las Meditaciones del Quijote, sobre todo en la recomendación primera: Lector... Se verá que Ortega enuncia allí menos, mucho menos, que lo que "dice". La idea sistematizable, "la súbita descarga de intelección", anuncia un largo camino, predetermina la tarea del filósofo que, atenido al reto de la circunstancia, vitalmente urgido, responde, con España invertebrada, El tema de nuestro tiempo, El espectador, La rebelión de las masas, etc., etc.

La realidad descubierta, realidad radical porque en ella radican todas las realidades, se llama vida humana y consiste en un estado de crisis normal del hombre. La explicación de la filosofía orteguiana, realizada periódicamente por Julián Marías, ha representado para este certero pensador una buena parte de su destino de escritor. La doctrina de Ortega nació desnuda, como la filosofía en su alborada parmenídica, provista de escasísimo aparato conceptual, portando en su entraña la más formidable incitación a desarrollar sus potenciales riquezas, que requieren un contexto filosófico apropiado, tarea más que suficiente para un par de generaciones. Marías acusa, en un escrito reciente, clara conciencia de la labor que exige una metafísica naciente o, lo que es igual, una nueva idea de la realidad: "Porque hay que decir que esas inflexiones de la filosofía no se deben nunca simplemente a la genialidad personal de los filósofos, que es ciertamente necesaria para llevarlas a cabo, sino que son impuestas y exigidas por la situación a que el hombre ha llegado, y por eso son preludiadas, anunciadas, ensayadas por la época entera. Por otra parte, sucede muchas veces que una nueva idea que ha surgido en el área histórica, suscitada por un cambio radical de situación, no alcanza su madurez filosófica, no se realiza de modo satisfactorio, no se logra. Piénsese, por ejemplo, en la idea de realidad cuya génesis se encuentra en la situación general definida por el cristianismo, y que espera aún su elaboración filosófica adecuada... Pues bien, la innovación filosófica de Ortega - que por cierto representará una posibilidad ex- 
tremadamente valiosa si algún día se intenta en serio esa elaboración- es de un orden de magnitud sumamente preciso o, si se prefiere, está claramente localizado en la historia del pensamiento: está situado en el centro de una de esas inflexiones. Sea lo que quiera de la cuestión de hasta donde se lleva esa idea de la realidad - se trata de la tarea de varias generaciones-, lo cierto es que su descubrimiento inequívoco y riguroso corresponde a Ortega".

La figura de Ortega cambia y se contrae al hilo de la lectura desordenada. El cambiante meditador que giraba rápido sobre sus facultades generosas de pensador ávido, de poeta, de crítico y ensayista, como un deslumbrante carrousel intelectual, arroja el lastre de la reflexión ocasional, ceñida a la circunstancia, y se muestra en su verdadera condición irrenunciable: la del filósofo, al que hay que buscar y encontrar por una u otra ruta. La obra crece al correr del tiempo, y es fácil advertir que queda cada vez menos de aquel pensador mozo que se placía en lanzar su doctrina envuelta en galas y primores de estilo, sofocada por la abundancia, casi abusiva, de temas diversos; en los que calmaba su apetito desproporcionado de curioso genial. La meditación se torna monocorde; fija, acosa, palpa una y otra vez la entraña de su hallazgo que compromete hasta el final el saber y la experiencia de su espíritu.

Mira la realidad radical, la vida, su vida, una y mil veces; comprime su materia fugitiva y extrae de ella esa suma de atributos, matices, particularidades misteriosas y desconocidas, de su azarosa entidad. La prosa barroca se encoge - antes sobrada y rica- admitiendo unos pocos términos decisivos, gastados por el uso y milagrosamente renovados ahora, antípodas de los neologismos a la alemana, que desorientan a algunos pedantes que todavía creen que la filosofía es una asignatura, un tema de examen escolar. La obsesión del filósofo se transmite al lector. Basta un pretexto, un tema mínimo, para que Ortega module la dramática melodía infusa en estas palabras: vida, vida humana, realidad extraña, realidad radical, que no nos es dada hecha, que es nuestro quehacer irrenunciable; el hom- 
bre no tiene otro remedio que estar haciendo algo para sostenerse en el mundo: Vida... realidad... quehacer.

Se requieren dos viajes para entender todo esto: uno hasta caer en la cuenta de que todo el tonelaje de pensamientos, alusiones y descubrimientos, fluyen de un hontanar secreto y ratifican una doctrina inicial sistemática; el otro desde el punto donde nace la doctrina, clara y terminantemente expresada, avanzando en la ruta del autor. Se puede señalar un tercer viaje, pero éste debe hacerlo el lector a través de su propia vida, prescindiendo de Ortega.

Se ha dicho, y es verdad, que en el primer libro - Meditaciones del Quijote - está prefigurada toda la obra orteguiana. Julián Marías señaló un punto más lejano, en el que advierte tenuemente todo el diseño: el ensayo Adán en el Paraíso.

¿No habrá, otra raíz más remota, en que se advierta la precoz lumbre mínima, la protoforma de un destino de pensador, todavía espectral y tenue, algo como un primer vagido de infante filósofo?

Retrocediendo en la lectura alcanzamos el punto de partida, el primer artículo que Ortega dió al público fechado el $10^{\circ}$ de diciembre de 1902. En estas Glosas podemos leer, con asombro e íntima conmoción: "Alejarse de las cosas para comprenderlas es lo que se llama presbicia. Hay que salir a su encuentro y chocar con ellas. ¿Quién conocerá su fuerza como el que entre en lid con las cosas? El dirá a los sentados en la gradería: ¡bien por mi vida, bien pica!"

El joven Ortega ya tenía en sus manos el arco y la flecha aristotélicos y se aprestaba a disparar su vida contra un blanco, aceptando alegremente lo real. Un destino fluvial caracterizará toda la obra: fecundarlo todo, estimular a todos. Algunos ocultan o desconocen la enorme deuda, aunque en los frutos y verdores de su labor no pueda disimularse la egregia paternidad. Recogiendo el desplante juvenil de aquella exclamación lejana decimos hoy: ¡Bien por su vida! El resto se lo quedan y lo sufren los que se calentaron al sol de esta gran circunstancia espiritual española que, según se ha ido viendo después de su muerte, bien les pica.

Circunstancia es resistencia del mundo en torno. Es difícil lograr 
un progresivo enriquecimiento de conexiones que organicen el caos de los hechos y de las cosas en un determinado sentido. Es difícil vivir. Ortega se torna reiterativo; recuerda a aquel médico que "sorprendido de que Fontenelle cumpliese en plena salud sus cien años, le preguntaba qué sentía, el centenario respondía: "Rien, rien $d u$ tout... seulement une certaine difficulté d'être". Debemos generalizar y decir que la vida, no sólo a los cien años, sino siempre, consiste en difficulté d'être. Su modo de ser es formalmente ser difícil, un ser que consiste en problemática tarea”.

Principio, transcurso y fin: el meollo de la ocupación orteguiana es la filosofía. La vida y la cultura se ordenan en un logos que, en un momento de buen humor, llamó del Manzanares, palpitante de matices, honduras y rotundos gestos hispánicos. Trascendiendo de la vida del hombre ha cambiado de rumbo la filosofía. Lo que en Dilthey se vislumbraba vagamente alcanza hoy sentido y vigencia. Un pensador tan equilibrado y sagaz como Ferrater Mora dice que para hablar de filosofía contemporánea en sentido estricto debemos referirnos a Bergson, James, Heidegger y Ortega. Los problemas que plantea la lectura del filósofo español son el mejor conducto para conocer la esencia y el drama del pensamiento de nuestro siglo. 